\title{
The role of zinc supplementation in the inhibition of tissue damage caused by exposure to electromagnetic field in rat lung and liver tissues
}

\author{
Baltaci AK ${ }^{1}$, Mogulkoc R ${ }^{1}$, Salbacak A ${ }^{2}$, Celik I ${ }^{3}$, Sivrikaya $\mathrm{A}^{4}$ \\ Selcuk University, Selcuklu Medical School, Department of Physiology, Konya, Turkey. baltaci61@yahoo.com
}

\begin{abstract}
Background: The objective of the present study was to examine the effects of zinc supplementation on the oxidant damage in lung and liver tissues in rats exposed to a $50-\mathrm{Hz}$ frequency magnetic field for $5 \mathrm{~min}-$ utes every other day over a period of 6 months.

Methods: The study included 24 adult male Sprague-Dawley rats, which were divided into the three groups in equal numbers: Group 1, the control group (G1); Group 2, the group exposed to an electromagnetic field (G2); and Group 3, the group, which was exposed to an EMF and supplemented with zinc (G3). At the end of the 6 -month procedures, the animals were decapitated to collect lung and liver tissue samples, in which MDA was analyzed using the "TBARS method (nmol/g/protein)", GSH by the "biuret method (mg/g/protein)" and zinc levels by atomic emission $(\mu \mathrm{g} / \mathrm{dl})$.

Results: MDA levels in lung and liver tissues in $\mathrm{G} 2$ were higher than those in $\mathrm{G} 1$ and $\mathrm{G} 3$, and the levels in $\mathrm{G} 3$ were higher than those in $\mathrm{G} 1$ ( $p<0.01$ ). As for $\mathrm{GSH}$ levels, $\mathrm{G} 3$ had $\mathrm{GSH}$ levels higher than $\mathrm{G} 1$ and $\mathrm{G} 2$, and $\mathrm{G} 2$ had $\mathrm{GSH}$ levels higher than $\mathrm{G} 1(\mathrm{p}<0.01)$. Zinc values in the liver and lung tissues were the highest in the Group 3 and the lowest in the Group $2(p<0.01)$.

Conclusion: Results of the study indicated that exposure to an electromagnetic field caused cellular damage in lung and liver tissues and zinc supplementation inhibited the inflicted cellular damage. Another important result of this study that needs emphasis was that exposure to an electromagnetic field led to a significant decrease in zinc levels in lung and liver tissues (Tab. 3, Ref. 23). Full Text in PDF www.elis.sk.

Key words: electromagnetic field, zinc, lipid peroxidation, lung, liver.
\end{abstract}

Electromagnetic fields, which are among the major environmental problems, pose a risk for human health when they exceed the pollution standards (1). Exposure to constant magnetic fields modifies the oxidative process (2). An increase in the incidence of coronary heart disease, brain tumour, leukaemia, lymphoma, soft tissue sarcoma, headache, depression, birth and reproductive anomalies and Alzheimer's disease in those who have been exposed to a magnetic field suggests that these sources cannot be used unrestrictedly $(3,4)$. Free radicals, whose major external sources include industrial pollution, ionized radiation, ultrasound and magnetic fields, are atoms, molecules or parts of these, and lead to neoplasia, neurodegeneration, inflammation and aging of the organism by causing oxidating stress (5). The high intensity and energy levels of electromagnetic fields and waves increase the formation of free radicals (6). By killing immune cells and displaying an increase parallel to the increase in $\mathrm{Ca}^{2+}$ in the plasma

${ }^{1}$ Selcuk University, Selcuklu Medical School, Department of Physiology, Konya, Turkey, ${ }^{2}$ Selcuk University, Meram Medical School, Department of Anatomy, Konya, Turkey, ${ }^{3}$ Selcuk University, School of Veterinary, Department of Histology, Konya, Turkey, and ${ }^{4}$ Selcuk University, Selcuklu Medical School Department of Biochemistry Konya,Turkey

Address for correspondence: A.K. Baltaci, Selcuk University, Selcuklu Medical School

Department of Physiology, 42075, Konya, Turkey. and tissues, radicals reduce the activity of natural killer cells and accelerate tumour development (7).

It has been noted that zinc, which is associated with several enzymes in the body, can prevent cellular damage by activating the antioxidant system (8). Additionally, previous studies have investigated whether zinc supplementation had a protective effect against the damage induced by a static magnetic field (9). Studies also have addressed the effect of electromagnetic fields on the levels of zinc in tissues (9). The present study aimed to examine the effects of long-term electromagnetic field exposure and zinc supplementation on lipid peroxidation in lung and liver tissues.

\section{Methods}

The study was conducted at Selcuk University Experimental Medicine Research and Application Center on 24 adult male Sprague-Dawley type rats. The study was approved by the ethics committee of the concerned centre.

Experiment Protocol: The animals used in the study were divided into 3 groups.

Control Group ( $G 1$ " $n=8$ ”): The group, which was fed with normal feed and tap water and not subjected to any procedure.

Group Exposed to an Electromagnetic Field ( $G 2$ " $n=8$ "): The group fed with normal feed and tap water and exposed to a mag- 
netic field for 5 minutes every other day over a period of 6 months.

Zinc-Supplemented Group Exposed to an Electromagnetic Field ( $G 3$ " $n=8$ "): The group, which in addition to being fed with normal diet and water was supplemented with $3 \mathrm{mg} / \mathrm{kg} / \mathrm{day} /$ rat intraperitoneal zinc sulphate for 6 months. The animals in this group were exposed to a magnetic field for 5 minutes every other day for 6 months.

The animals were decapitated at the end of the experiment and liver and lung tissues were collected to determine the levels of MDA, GSH and zinc.

\section{Formation of a Magnetic Field:}

The plastic cages were wound by a single line of isolated copper wire with a $0.30 \mathrm{~mm}$ diameter. The decision regarding the number of windings and the wire diameter was based on the principle of obtaining the desired magnetic field intensities while a reasonable level of current passed through the winding. Thus, it was ensured that the wire did not warm and the animals were not subjected to any heat stress.

The windings around the cages were fed with a power supply transformer whose output voltage was $12 \mathrm{~V}$ and output power was $30 \mathrm{~W}$. The supply voltage of the primer of this transformer was controlled by a dimmer loop to obtain the desired field intensity. For precision arrangements, the windings were supplied from a mechanical rheostat. An appropriate voltage regulator was used on the supply transformer in order to prevent the effects of the fluctuations in the network voltage.

The network alternative current frequency used in our country is $50 \mathrm{~Hz}$ and $50-\mathrm{mG}$ magnetic field intensity was formed in the study. The animals in the control group were also kept in the cages where the experimental groups were kept, but without connecting the electrodes of the winding to the power supply circuit.

Measurement of the magnetic field intensity: A compact wideband precision (resolution: $1 \mathrm{nT} / 0.01 \mathrm{mG}$ on $20 \mathrm{mG}$ range, accuracy: $\pm 1 \%+1$ count) magnetometer (Walker Scientific, USA; Broad Band AC magnetometer, BBM 3 D) was used for this purpose.

Cages: In order to prevent possible distortions and form a homogenous magnetic field, the cages, in which the animals would be exposed to the magnetic field, were specially manufactured from polyvinyl chloride (PVC). The cages measured $35 \times 25 \times 25$ $\mathrm{cm}$ in size. The feeding bowls and bottles of the animals were also made entirely of glass and PVC. With a view to minimizing the effect of environmental magnetic fields, the cages were placed in places where background magnetic field strength was the lowest $(0.1 \mathrm{mG})$ in the room. Mean temperature was $22^{\circ} \mathrm{C}$ and relative humidity was between 55 and $60 \%$ in the room.

\section{Biochemical Analyses}

Tissue MDA Analyses: Lung and liver tissue samples were homogenized with $150 \mathrm{mMol} \mathrm{KCl}$ at $+4{ }^{\circ} \mathrm{C}$ to obtain a $10 \%$ homogenate (Microsan Ultrasonic Cell Disruptor Misonic). Two $\mathrm{ml}$ of $\mathrm{HClO} 4$ was added to $2 \mathrm{ml}$ of homogenate and centrifuged at $3000 \mathrm{rpm}$ for 15 minutes. MDA level was evaluated in the supernatant. Then, $3 \mathrm{ml} \mathrm{H} 3 \mathrm{PO} 4,1 \mathrm{ml} 0.675 \%$ thiobarbituric acid and $0.5 \mathrm{ml}$ of homogenate were mixed, and the mixture was kept in a boiling water bath for 45 minutes (10). MDA levels were measured at $532 \mathrm{~nm}$ and determined as $\mathrm{nmol} / \mathrm{gram} /$ protein.

Tissue GSH Analyses: In order to obtain a $10 \%$ homogenate, lung and liver tissue samples were homogenized with $150 \mathrm{mMol}$ $\mathrm{KCl}$ at $+4{ }^{\circ} \mathrm{C}$ (Microsan Ultrasonic Cell Disruptor Misonic) and then centrifuged at $3000 \mathrm{rpm}$ for 15 minutes. GSH level in the supernatant was determined using the Ellman method (11). Tissue protein concentration was determined by a biuret method. GSH level was established as $\mathrm{mg} / \mathrm{g} /$ protein.

Determination of Zinc Levels in Lung and Liver Tissues

In order to prevent contamination, lung and liver tissue samples were put in capped polyethylene tubes washed with $\mathrm{NHO} 3$ and deionized water. The samples were stored at $-35^{\circ} \mathrm{C}$ until the time of analysis. For the analysis, liver tissue was ground into a fine powder in a mortar and wet weight of the tissue was recorded. This powder was added concentrated $\mathrm{H} 2 \mathrm{SO} 4$ and concentrated $\mathrm{HNO} 3$ (gram tissue $/ \mathrm{ml} \mathrm{H} 2 \mathrm{SO} 4 / \mathrm{ml} \mathrm{HNO} 3=1 / 1 / 10)$. Then it was kept in a closed-system microwave oven (CEM-Marsx5) at 170 psa pressure and $200{ }^{\circ} \mathrm{C}$ temperature for 20 minutes. The final volumes of the samples were brought up to $25 \mathrm{ml}$ by adding deionized water and the samples were kept waiting for half an hour before being read. The analysis procedure was carried out using the Atomic Emission (ICP-AES) apparatus in the Soil Department of S.U. Faculty of Agriculture. The results were calculated as $\mathrm{mg} / \mathrm{L}$.

Statistical Analysis: Statistical analysis was conducted using the SPSS statistics software. The results were presented as mean \pm SD. A variance analysis was carried out and the differences among groups were determined by the LSD (The Least Significant Difference) test. Values for which $\mathrm{p}<0.05$ were accepted significant.

\section{Results}

When lung and liver MDA levels were examined, it was found that this parameter was higher in the Group 2 than in the Groups 1 and 3 ( $p<0.01)$ (Tab. 1). Although MDA levels in the lung tissue of the EM field + zinc supplementation group were higher than those in the control group (group 1), they were lower than the levels in the group exposed to EM only ( $\mathrm{p}<0.01)$ (Tab. 1).

An examination of the GSH levels in lung and liver tissues showed that the GSH levels in the Group 3 were higher than the levels in the Groups 1 and 2, and the levels in the Group 2 were higher than those in the Group $1(\mathrm{p}<0.01)$ (Tab. 2).

Zinc values in the liver and lung tissues were the highest in the Group 3 and the lowest in the Group $2(\mathrm{p}<0.01)$ (Tab. 3).

Tab. 1. MDA values in the lung and liver tissues of study groups.

\begin{tabular}{lcc}
\hline Groups (n=8) & $\begin{array}{c}\text { Lung MDA } \\
\text { (nmol/g/protein) }\end{array}$ & $\begin{array}{c}\text { Liver MDA } \\
\text { (nmol/g/protein) }\end{array}$ \\
\hline The Control Group (G1) & $22.82 \pm 8.14 \mathrm{c}$ & $20.60 \pm 5.45 \mathrm{~b}$ \\
\hline $\begin{array}{l}\text { The Group Exposed to an Electro- } \\
\text { magnetic Field (G2) }\end{array}$ & $85.64 \pm 10.50 \mathrm{a}$ & $122.75 \pm 32.56 \mathrm{a}$ \\
\hline $\begin{array}{l}\text { The Zinc-Supplemented Group Expo- } \\
\text { sed to an Electromagnetic Field (G3) }\end{array}$ & $49.45 \pm 6.35 \mathrm{~b}$ & $40.65 \pm 6.20 \mathrm{~b}$ \\
\hline *Means with different letters in the same column are statistically significant.
\end{tabular}


Tab. 2. GSH values in the lung and liver tissues of study groups.

\begin{tabular}{lcc}
\hline Groups & $\begin{array}{c}\text { Lung GSH } \\
(\mathrm{mg} / \mathrm{g} / \mathrm{prote})\end{array}$ & $\begin{array}{c}\text { Liver GSH } \\
(\mathrm{mg} / \mathrm{g} / \mathrm{protein})\end{array}$ \\
\hline The Control Group (G1) & $105.45 \pm 17.20 \mathrm{c}$ & $15.65 \pm 6.10 \mathrm{c}$ \\
\hline $\begin{array}{l}\text { The Group Exposed to an Electro- } \\
\text { magnetic Field (G2) }\end{array}$ & $205.36 \pm 19.75 \mathrm{~b}$ & $28.45 \pm 3.50 \mathrm{~b}$ \\
\hline $\begin{array}{l}\text { The Zinc-Supplemented Group Expo- } \\
\text { sed to an Electromagnetic Field (G3) }\end{array}$ & \\
\hline *Means with different letters in the same column are statistically significant.
\end{tabular}

Tab.3. Zinc values in the lung and liver tissues of study groups.

\begin{tabular}{lcc}
\hline Groups & $\begin{array}{c}\text { Lung zinc } \\
(\mathrm{mg} / \mathrm{L})\end{array}$ & $\begin{array}{c}\text { Liver zinc } \\
(\mathrm{mg} / \mathrm{L})\end{array}$ \\
\hline The Control Group (G1) & $3.85 \pm 0.98 \mathrm{~b}$ & $4.15 \pm 1.05 \mathrm{~b}$ \\
\hline $\begin{array}{l}\text { The Group Exposed to an Electro- } \\
\text { magnetic Field (G2) }\end{array}$ & $1.45 \pm 0.20 \mathrm{c}$ & $2.55 \pm 0.90 \mathrm{c}$ \\
\hline $\begin{array}{l}\text { The Zinc-Supplemented Group Expo- } \\
\text { sed to an Electromagnetic Field (G3) }\end{array}$ & $6.72 \pm 1.05 \mathrm{a}$ & $7.50 \pm 1.20 \mathrm{a}$ \\
\hline *Means with different letters in the same column are statistically significant.
\end{tabular}

\section{Discussion}

In the present study, MDA levels increased significantly in the lung and liver tissues of rats exposed to the electromagnetic field with a $50-\mathrm{Hz}$ frequency in a long term (6 months) (the Group 2). Toxic oxygen free radicals are highly reactive and bring about pathological outcomes by damaging biomolecules, enzymes, membranes, proteins and lipids $(12,13)$. The impact of the electromagnetic field on different tissues depends on the duration of exposure and the type of tissue (13). Electromagnetic fields have been demonstrated to increase free radical formation in several studies $(14,15)$. The fact that exposure to the electromagnetic field has been shown to cause lipid peroxidation in the mouse liver (14) or, similarly, that exposure to the electromagnetic field has been reported to increase MDA formation in the liver and brain of rats (15), is parallel to our findings. Levels of GSH in the rats exposed to the electromagnetic field (the Group 2) in our study were found higher, relative to the levels in the control group. This finding indicated that although the antioxidant system was activated in the rats exposed to the electromagnetic field, it failed to inhibit the oxidative damage. Likewise, Seyhan and Canseven (16) reported in a similar study that exposure to a $50-\mathrm{Hz}$ electromagnetic fields affected the antioxidant defence systems in a number of organs like the spleen, skin, lung, kidney and brain. The electromagnetic field used in the concerned study was identical with the one we used in our study and supported our findings. In another study, an acute exposure to the electromagnetic field was found to decrease GSH levels in the liver (17). The fact that we have found decreased GSH levels in our study is congruent with the findings of the concerned study.

An examination of the part of our study about the lung tissue demonstrates that MDA levels in this tissue increased with the exposure to the electromagnetic field. Although GSH levels were also elevated in response to the increased MDA levels, they failed to restore the MDA levels to control values. These findings showed that the increased tissue damage in the lung tissue resulting from exposure to electromagnetic fields could not be prevented, despite the enhanced antioxidant system activity. Similarly, Güler et al. (18) reported in their study that exposure to a $50-\mathrm{Hz}$ electromagnetic field elevated SOD and TBARS levels in the lung tissue.

Liver MDA levels in the Group 3, which was exposed to an electromagnetic field and supplemented with zinc, were lower than those in the non-supplemented Group 2. These findings indicated that zinc supplementation to rats exposed to an electromagnetic field significantly reduced levels of MDA, which is an indicator of tissue damage in the liver. Zinc has an activating effect on the antioxidant system (8). Several researchers reported that zinc deficiency in the organism caused lipid peroxidation $(19,20,21)$. The results we obtained in the Group 3 in our study are consistent with the studies highlighting the antioxidant character of zinc.

Our results also demonstrated that GSH levels in the group exposed to the electromagnetic field and supplemented with zinc (the Group 3) were higher than those in the Groups 1 and 2. The fact that GSH levels were higher in the Group 2 than in the Group 1 demonstrated that antioxidant system activity was enhanced in the animals exposed to the electromagnetic field in order to prevent tissue damage. Higher GSH levels also showed that zinc supplementation in the Group 3 made the increase in the antioxidant system activity more marked. The fact that GSH levels in the Group 3 were higher indicated that zinc activated the antioxidant system and inhibited the lipid peroxidation caused by the exposure to the electromagnetic field. Previous studies, where zinc supplementation was found to produce a protective effect on the liver (22) and to balance redox reactions in the lung tissue, support the results we have obtained $(9,23)$.

Lung and liver zinc levels in the Group 3, which was exposed to the electromagnetic field and supplemented with zinc, were higher than those in the Groups 1 and 2. These findings show that the tissue levels of zinc increased as a result of the supplementation of the concerned element. However, it should be noted that zinc levels in the lung and liver tissues of the Group 2, which was exposed to the electromagnetic field, were lower than the levels in the control group. It was reported in the previous study that zinc levels in the liver and kidney tissues of rats exposed to an electromagnetic field for 1 hour daily for a period of 1 month remained unchanged (9). However, electromagnetic field- exposure for 6 months in our study significantly reduced the zinc levels in the liver and lung tissues of rats. Reduced levels of zinc, found in the present study, are seen to result from long-term exposure to an electromagnetic field. The difference between these results is attributable to duration of exposure. However, it was observed that zinc supplementation together with electromagnetic field exposure restored the reduced zinc levels.

After an overall evaluation of the results of the study, one can come to the following conclusions:

1. Long-term exposure to an electromagnetic field causes lipid peroxidation in the lung and liver tissues of rats.

2. Long-term exposure to an electromagnetic field may lead to a decrease in lung and liver tissue zinc. 
3. Zinc supplementation inhibits the cellular damage caused by electromagnetic field exposure in rat lung and liver tissues, while restoring the reduced tissue zinc levels.

\section{References}

1. Yeniterzi M, Avunduk MC, Baltaci AK, Aribas OK, Gormus N, Tosun E. The histopathological changes in the rats caused by magnetic field of $50 \mathrm{~Hz}$ frequency. Selcuk J Med 2002; 18: 39-51.

2. Politański P, Rajkowska E, Pawlaczyk-Luszczyńska M, Dudarewicz A, Wiktorek-Smagur A, Sliwińska-Kowalska M, Zmyślony M. Static magnetic field affects oxidative stress in mouse cochlea. Int J Occup Med Environ Health 2010; 23 (4): 377-384.

3. Stuchly MA, Lecuyer DW, McLean J. Cancer promotion in a mouseskin model by a $60-\mathrm{Hz}$ magnetic field: I. Experimental design and exposure system. Bioelectromagnetics 1991; 12 (5): 261-271.

4. Yasui M, Otaka Y. Facility for chronic exposure of rats to ELF magnetic fields. Bioelectromagnetics 1993; 14 (6): 535-544.

5. Ciejka E, Goraca A. Influence of low magnetic field on lipid peroxidation. Pol Merkur Lekarski 2008; 24 (140): 106-108.

6. Chignell CF, Sik RH. The effect of static magnetic fields on the photohemolysis of human erythrocytes by ketoprofen. Photochem Photobiol 1998; 67 (5): 591-595.

7. Shau H, Kim AT, Hedrick CC, Lusis AJ, Tompkins C, Finney R, Leung DW, Paglia DE. Endogenous natural killer enhancing factor - B increases cellular resistance to oxidative stresses. Free Radic Biol Med 1997; 22 (3): 497-507.

8. Powell SR. The antioxidant properties of zinc. J Nutr 2000; 130 (Suppl 5S): 1447-1454.

9. Salem A, Hafedh A, Rached A, Mohsen S, Khémais BR. Zinc prevents hematological and biochemical alterations induced by static magnetic field in rats. Pharmacol Rep 2005; 57 (5): 616-622.

10. Draper HH, Hadley M. Malondialdehyde determination as index of lipid peroxidation. Methods Enzymol 1990; 186: 421-431.

11. Atroshi F, Sankari S, Osterberg S, Sandholm M. Variation of erythrocyte glutathione peroxidase activity in Finn sheep. Res Vet Sci 1981; 31 (3): 267-227.

12. Emre M, Cetiner S, Zencir S, Unlukurt I, Kahraman I, Topcu Z. Oxidative stress and apoptosis in relation to exposure to magnetic field. Cell Biochem Biophys 2011; 59 (2): 71-77.
13. Seyhan N, Güler G. Review of in vivo static and ELF electric fields studies performed at Gazi Biophysics Department. Electromagn Biol Med 2006; 25 (4): 307-323.

14. Watanabe Y, Nakagawa M, Miyakoshi Y. Enhancement of lipid peroxidation in the liver of mice exposed to magnetic fields. Ind Health 1997; 35 (2): 285-290.

15. Romodanova EA, Paranich AV, Chaikina LA. Effect of chronic effect of the electrostatic field on various biochemical indicators of the tissues. Fiziol Zh 1990; 36 (3): 30-34.

16. Seyhan N, Canseven AG. In vivo effects of ELF MFs on collagen synthesis, free radical processes, natural antioxidant system, respiratory burst system, immune system activities, and electrolytes in the skin, plasma, spleen, lung, kidney, and brain tissues. Electromagn Biol Med 2006; 25 (4): 291-305.

17. Martínez-Sámano J, Torres-Durán PV, Juárez-Oropeza MA, ElíasViñas D, Verdugo-Díaz L. Effects of acute electromagnetic field exposure and movement restraint on antioxidant system in liver, heart, kidney and plasma of Wistar rats: a preliminary report. Int J Radiat Biol 2010; 86 (12): 1088-1094.

18. Güler G, Seyhan N, Aricioğlu A. Effects of static and $50 \mathrm{~Hz}$ alternating electric fields on superoxide dismutase activity and TBARS levels in guinea pigs. Gen Physiol Biophys 2006; 25 (2): 177-193.

19. Ozturk A, Baltaci AK, Mogulkoc R, Oztekin E, Sivrikaya A, Kurtoglu E, Kul A. Effects of zinc deficiency and supplementation on malondialdehyde and glutathione levels in blood and tissues of rats performing swimming exercise. Biol Trace Elem Res 2003; 94 (2): 157-166.

20. Shaheen AA, el-Fettah AA. Effect of dietary zinc on lipid peroxidation, glutathione, protein levels and superoxide dismutase activity in rat tissues. Int J Biochem Cell Biol 1995; 27 (1): 89-95.

21. Biaggio VS, Pérez Chaca MV, Valdéz SR, Gómez NN, Gimenez MS. Alteration in the expression of inflammatory parameters as a result of oxidative stress produced by moderate zinc deficiency in rat lung. Exp Lung Res 2010; 36 (1): 31-44.

22. Dhawan D, Goel A. Further evidence for zinc as a hepatoprotective agent in rat liver toxicity. Exp Mol Pathol 1995; 63 (2): 110-117.

23. Mehta AJ, Joshi PC, Fan X, Brown LA, Ritzenthaler JD, Roman J, Guidot DM. Zinc supplementation restores PU.1 and Nrf2 nuclear binding in alveolar macrophages and improves redox balance and bacterial clearance in the lungs of alcohol-fed rats. Alcohol Clin Exp Res 2011; doi: 10.1111/j.1530-0277.2011.01488.x. 